
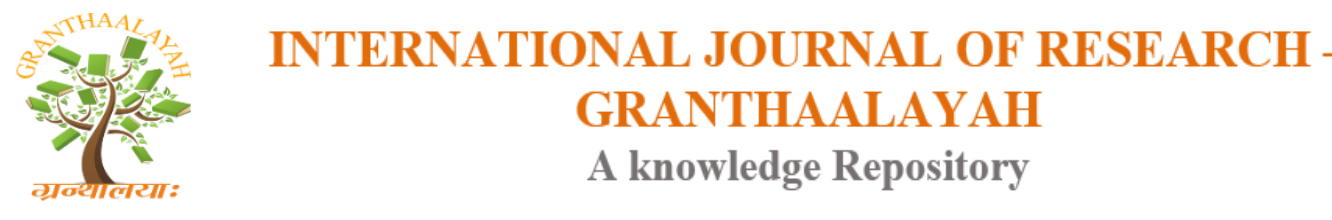

Management

\title{
FINANCIAL INCLUSION AND WOMEN EMPOWERMENT: A GENDER PERSPECTIVE
}

\author{
Bincy George ${ }^{1}$, K.T.Thomachan ${ }^{2}$ \\ ${ }^{1}$ MA Economics, St. Joseph's College, Devagiri, Calicut Kerala - 673008, India \\ ${ }^{2}$ Associate professor, Department of Economics, St. Joseph's, CollegeDevagiri, Calicut, Kerala - \\ 673008, India
}

\begin{abstract}
This paper examines women empowerment associated with financial inclusion. Financial inclusion is delivery of banking services at an affordable cost to the vast sections of disadvantaged and the low-income groups. The various financial services include access to saving, credit, insurance, bank account etc. The access to financial services helps women in their social and economic development. It is noted that access to financial service through financial inclusion do have impact upon the social and financial empowerment of women leading to their overall empowerment.

Keywords: Financial Inclusion; Women Empowerment; Financial Services; Financial Literacy; Financial Exclusion; Chi Square.

Cite This Article: Bincy George, and K.T.Thomachan. (2018). "FINANCIAL INCLUSION AND WOMEN EMPOWERMENT: A GENDER PERSPECTIVE.” International Journal of Research - Granthaalayah, 6(5), 229-237. https://doi.org/10.29121/granthaalayah.v6.i5.2018.1443.
\end{abstract}

\section{Introduction}

As India aims inclusive growth, financial inclusion is a major step which leads to that aim. Financial inclusion ensures that a range of financial services are available to every individual and that the individual understands and accesses those services. These include basic, no-frills banking account for making and receiving payments, money transfer facilities, small loans, overdrafts and insurance. A committee on financial inclusion headed by Dr. C Rangarajan in 2008 defined financial inclusion as: "The process of ensuring access to financial services and timely and adequate credit where needed by vulnerable groups such as weaker sections and low-income groups at an affordable cost." In the Indian context, the term financial inclusion was used for the first time in April 2005, by Y V Reddy. Later on, this concept came to be widely used in India and abroad. Mangalam became the first village in India where all households were provided banking facilities. The government Of India recently announced Pradhan Mantri Jan Dhan Yojana, a national financial inclusion mission which aims to provide bank accounts to the people. 
In India where women constitute approximately $46 \%$ of total population majority of them denied to opportunities and rights because of their financial dependence. Through various methods by banks, government tries to make women economically independent. But access to formal financial system is not yet reached to the entire Indian population. Access to credit is often limited for women who do not have assets such as land and property. Limited literacy particularly financial literacy and lack of understanding often plays as a hindrance in accessing of financial services. Financial inclusion is needed for women as it helps them to have a regular saving along with enabling them to pay for micro insurance and obtain credit. Financial inclusion makes women informed about their role and right in economic development and other information for empowerment. Financial inclusion will enable women for economic decision making, enhancing purchasing power, control over loans and control over income and savings, borrow for investments and insure against risk.

Financial literacy helps to compare and select the best products for women's need and empower them to exercise their rights and responsibilities. It enables women to act financially smart by providing knowledge and skills to understand financial planning, savings, basics of banking, understanding need of household budgeting, cash flow management, asset allocation to meet financial goal etc. Financial inclusion helps women in social and economic development as it creates or gives awareness about various programmes which aims at health, education, water and sanitation, and legal rights. Savings are important for women to build security and to decrease vulnerability. Financial inclusion of women in insurance sector enables poor women to overcome risks health, old age etc. The credit or loan facilities provided help women to start their own business and make them economically independent. But the problem here is that poor women cannot provide collateral and are excluded from many loan programmes. Also, illiterate women are not able to understand the complicated loan procedures. Micro finance should provide access to loans for women which will encourage women entrepreneurship. While preparing programmes for financial inclusion gender related barriers in accessing financial services should also be checked.

Kerala has made remarkable achievements in its banking sector compared to other states in India. The banking sector in Kerala achieved 100 per cent financial inclusion guaranteeing at least one bank account in each household and banking facilities within reach of all the people in the 14 districts of the State. Kerala also attained the top spot in the CRISIL Inclusix score of 90.9 which measures the extent of financial inclusion. CRISIL Inclusix is measured on a scale of 0 to 100, where 100 is the maximum score achievable. regarding Despite this achievement, it has been evident that financial awareness has not been fully able to penetrate into the rural population of the Kerala especially of women. Non-institutional credit givers in the form of money lenders still continue to grasp the women in their clutches.

While discussing about financial inclusion there is another term which needs our attention, i.e., financial exclusion. It was in 1999, that the term financial exclusion seems first to have been used in a broader sense to refer to people who have constrained access to mainstream financial services (Kempson and Whyley, 1999).

The general consensus is that it refers to people who have difficulty accessing appropriate financial services and products in the mainstream financial services market. Two aspects of this definition 
are important: First the reference to appropriate products and secondly to the mainstream financial services market - as much of the exclusion appears to arise from a failure of the mainstream commercial providers to supply a range of products and services that are appropriate to the needs of all sections of society.

Financial exclusion leads to social exclusion. The excluded section comprises of the marginal farmers, landless laborers, self-employed, and unorganized sector, enterprises, urban slum dwellers, migrants, ethnic minorities and socially excluded group, senior citizens and women (Rangarajan Committee Report).

\section{Statement of The Problem}

Financial Inclusion means the delivery of financial services at an affordable cost to the vast sections of disadvantaged groups of society which may bring about their empowerment. But access to formal financial system is not yet reached to the entire population of India. Gender inequality still remains as a major constraint for financial inclusion of women. When women are financially independent they can make decisions in family. This will make them economically independent and empowered. In India where women constitute approximately $46 \%$ of total population majority of them are denied to opportunities and rights became of their financial dependence.

The value proportion of expanding women's financial inclusion is receiving increasing attention. There is solid evidence in recent literature that indicates women's financial inclusion leads to significant benefits for the economy and for societies in terms of economic growth, reduced inequality and well-being in societies. Yet women, 50\% of the world's population, lag behind in access and wage of financial products and services. While significant advances in financial inclusion for both men and women occurred between 2011 and 2014, the gender gap permits.

Consistent with their multiple roles as economic actors and caretakers of their familiar women's financial inclusion leads to benefits at the enterprise level and at the household level. Providing occur to formal savings instruments allows women to increase consumption that is beneficial to their familiar in addition to increasing productive investment.

There prevails many social stigma regarding position of women in society. Their roles are closely linked to their socially defined gender roles, responsibilities and social structure. Gender inequality is still a major constrain for financial inclusion of women. Women's financial inclusion can make an important contribution to women's economic and broader empowerment. A Financial inclusion program needs to consider whether or not to promote access to other services such as health, education for maximizing the program's impact on women's empowerment. Programs for women's financial inclusion should consider the context in which they are living and multiple levels of exclusion and discrimination. Gender related barriers that inhibit women's ability to access financial services and block women empowerment should be considered carefully while preparing these programs.

India has, for a long time, recognized the social and economic imperatives for broader financial inclusion and has made an enormous contribution to economic development by finding innovative ways to empower the poor, women and other disadvantaged group. Starting with the 
nationalization of banks, priority sector lending requirements for banks, lead bank scheme, establishment of regional rural banks (RRBs), service area approach, self-help group-bank linkage programme, etc., multiple steps have been taken by the Reserve Bank of India (RBI) over the years to increase access to the weaker segments of society. Financial inclusion is a great step to for women empowerment in India. But to achieve this, the government should provide a less perspective environment in which banks are free to pursue the innovations necessary to reach low income consumers and still make a profit. Financial service providers should learn more about the consumers and new business models to reach them. The author of this paper discusses the pertinent issues of financial inclusion comprising of narrower and broader aspect with respect to women empowerment, the importance of the financial literacy and the detailed perspective of the pros and cons and steps to be taken to improve the reach of financial and banking services at grassroots level. Financial inclusion is the road that India needs to travel toward becoming a global player. Financial access to all sections of people will attract global market players to our country and that will result in increasing employment and business opportunities. Inclusive growth will act as a source of empowerment and allow people to participate more effectively in the economic and social process.

\section{Literature Review}

There are very limited studies, which are directly relevant to the present study. They have been taken from journals, articles, PhD thesis and unpublished research works.

Sharma and Pais (2008) analyzed the Indian history with the concept of financial inclusion started in the year of 1904 as cooperative movement, and then it gained momentum in 1969, when 14 major commercial banks of the countries were nationalized and lead bank scheme was introduced shortly thereafter from that year the majority of bank branches were opened in large number across the country and even in the areas which were hitherto being neglected. However, there was severe gap in financial assessment which needed special attention. Many studies have proved that lack of inclusion was rather exclusion from the banking system which resulted in a loss of 1 percent to the GDP. Thus, the Reserve Bank of India concluded that the financial inclusion was not just a sociopolitical imperative but also an economic one and realized the gravity of the problem. Finally, the Reserve Bank of India made the Mid Term Review of Monetary Policy (2005-06), urged the banks to make financial inclusion as one of their prime objectives.

Singh (2012) discussed that as the poverty level declined and households have greater levels of discretionary incomes, they would be first time financial servers. They would, therefore, need to have easy access to formal financial systems to get into the banking habit. Banks would need to innovate and devised newer methods of including such customers into their fold. Innovation in the form of business facilitators and correspondents would be needed for banks to increase their outreach for bank to ensure financial inclusion. He emphasized the financial inclusion as a great step to alleviate poverty in India. But to achieve this, the government should provide a less perspective environment in which banks were free to pursue the innovations necessary to reach low income consumers and still make a profit. Financial service providers should learn more about the consumers and new business models to reach them. New entrants to the banking, system need household at their doorstep. There has been a burst of entrepreneurship across the country, spanning rural, and semi-urban and urban areas. This has to be nurtured and financed. It was only 
through growth of enterprises across all size and that competition would be fostered. With the increasing liberalization and higher economic growth, the role of the banking sector was poised to increase in the financing pattern of economic activities within the country. Financial inclusion would strengthen financial depending and provide resources to the banks to expand credit delivery. He concluded that financial inclusion would lead to financial development in our country which will in turn help to accelerate economic growth.

Pratisha Padmasri Deka (2015) states that in India where women constitute $46 \%$ of total population majority of them are denied to opportunities and rights due to their financial dependence. Financial inclusion is much needed for women as it helps in increasing amount of regular savings along with enabling women to pay for micro insurance and obtain credit. It also helps in increasing income from employment and micro enterprise, usage of mainstream banking services that offer appropriate designed products and service. In other words financial inclusion make women informed about their role and right in economic development to improve access to markets and other information for overall empowerment. By helping women to meet their practical needs, micro finance may help women to gain respect and achieve more in their socially defined roles along with wellbeing. This paper mainly deals with-Importance of women's financial inclusion, Women's specific financial needs in respect to men's, Functions of finance and role of women, Growth, development and financial inclusion, Financial literacy as a tool for women empowerment, Institutional framework in India for financial education, Economic and social development of women and financial inclusion, Gender inequality and lack of access to financial services, Certain issues and aspects related with financial inclusion and women empowerment. The paper calls for women empowerment by means of effective financial inclusion and financial literacy by studying the relationship between women empowerment and financial inclusion.

FATF (2011) emphasized that disadvantaged and other vulnerable groups such as SC, ST and women, including low income households, handicapped, individuals in rural communities and undocumented migrants, in both developed and developing jurisdictions, were more likely to be excluded from the formal, regulated financial sector, because of other barriers such as problems in meeting the documentary and other requirements, non-awareness, wrong perceptions, limited knowledge, high cost etc. Underserved clients represent a very heterogeneous category with very different risk profiles in different jurisdictions. As a consequence, they could not be classified as low risk clients on the sole basis that they were financially excluded.

Michael Chibba(2009) noted that financial inclusion is an inclusive development and poverty reduction strategy that manifests itself as part of the emerging FI-PR-MDG nexus. However, given the current global crises, the need to scale- up financial inclusion is now perhaps more important as a complementary and incremental approach to work towards meeting the MDGs than at any other time in recent history. (Michael Chibba (2009), Financial Inclusion, Poverty Reduction and the MDGs, European Journal of Development Research vol.21).

\section{Objectives}

The major objectives of the study are: 
1) To assess the nature and extend of financial inclusion in India.

2) To analyze role of financial inclusion and financial literacy as a tool for women empowerment.

3) To understand the various financial services availed by women through banks and its impact on their economic and financial independence

\section{Data and Methodology}

To understand the extend of financial inclusion in India and among women data has been collected from both primary and secondary sources. Primary data for the study has been collected from 100 samples by using random sampling method. The study is purely based on sample surveys conducted among women in Kozhikode locality. The sample survey was conducted by using a questionnaire.

The secondary data has been collected from financial inclusion surveys and reviews collected from various articles published in several journals, E- journals and websites of CRISIL, RBI, Ministry of finance, EPW and various other references. For analysing the data and arrive at the logical conclusions, mathematical tools like percentage, ratios etc. and statistical tools like mean, standard deviation etc. have been used. To understand whether financial inclusion leads to women empowerment $\chi 2$ test of association has been used.

\section{Chi-square Test $(\chi 2)$}

To assess the association between socio-economic characteristics (income, sex, religion and occupation) and the extent of financial inclusion, we use the Chi-square test for independence. The hypothesis for independence is:

Ho: The two classification variables are independent of each other.

H1: The two classification variables are not independent.

The Chi-square test statistic for independence is:

$$
x^{2}=\sum \frac{(O-E)^{2}}{E}
$$

\section{Results and Discussion}

This section outlines the major findings of sample survey. It examines the various socioeconomic characteristics of the sample consumers and financial independence of women in the study area and the level of their empowerment. The analysis about various financial services availed by women are important as it leads them to empowerment. This study focusses mainly on women doing their own business or entrepreneurial activities through financial services like loans and savings. Thus, reveals the fact that the accessibility of financial services leads to their empowerment. The sample survey was conducted by using a questionnaire.

The study reveals the awareness level of respondents regarding the various financial inclusion schemes like no frills account, direct cash transfer scheme, simplification of KYC norms. 
Table 1: Level of awareness about financial inclusion schemes

\begin{tabular}{|l|l|l|l|l|}
\hline \multirow{2}{*}{ Financial service scheme } & \multicolumn{3}{|c|}{ Level of awareness } & Total \\
\cline { 2 - 5 } & 1 & 2 & 3 & \\
\hline No frills account scheme & 3 & 8 & 89 & 100 \\
\hline Overdraft facilities & 40 & 33 & 27 & 100 \\
\hline DBT schemes & 3 & 5 & 92 & 100 \\
\hline SHG bank linkage proramme & 10 & 12 & 78 & 100 \\
\hline Jan Dhan Yojana & 0 & 3 & 97 & 100 \\
\hline Relaxation of KYC norms & 5 & 12 & 83 & 100 \\
\hline Micro finance without collateral & 29 & 59 & 12 & 100 \\
\hline
\end{tabular}

Source: Sample Survey

Where, 1 - low awareness level, 2 - medium awareness level, 3 - high awareness level

As the table suggests, there is difference in the awareness level of 100 respondents regarding different financial awareness schemes. There is high level of awareness regarding DBT schemes, Jan Dhan Yojana, no frills account, etc. among the respondents. When it comes to the overdraft facilities the level of awareness is low. While observing the information in this table we are able to understand how much people are aware about different financial inclusion schemes provided by the government in its plan to bring people under the umbrella of financial inclusion. This shows whether financial literacy programmes are efficient or not.

\section{Access to financial services and women empowerment}

Financial inclusion is the expanding outreach of banking or financial services at an affordable cost. This also indicates whether access to financial services helps them to make their own decisions and whether they are financially independent. The various financial services include access to saving, credit, insurance, bank account etc. The access to financial services helps them in their social and economic development. Saving helps women to plan and invest in small ventures which they can run successfully with the help of loan. Insurance enables women to overcome risk to health, old age, death etc.

We examine whether there is any association between decision making power in the family leading to social empowerment of women. To assess this association, $\chi 2$ test of independence has been performed. Test results are given in Table 2.

Table 2: Participation in decision making within family

\begin{tabular}{|l|l|l|l|l|}
\hline \multirow{2}{*}{ Category } & \multicolumn{2}{c|}{ Decision making } & \multirow{2}{*}{ Total } & \\
\cline { 2 - 4 } & Employed women & Unemployed women & & \\
\hline Women & 31 & 2 & 33 & \\
\hline Both men and women & 45 & 22 & 67 & $\boldsymbol{\chi} 2=8.6902$ \\
Total & 76 & 24 & 100 & $(0.003199) *$ \\
\hline
\end{tabular}

Source: Sample Survey

(Figure in brackets is p-value, $*$ indicates significance at $5 \%$ level.)

As the table suggests there is association between decision making power in the family leading to social empowerment of women $(\chi 2=8.6902, \mathrm{P}=0.003199)$. 
To assess the association between access to loan and financial independence which leads to economic empowerment of women, $\chi 2$ test of independence has been performed. Test results are given in Table 3. Out of 100 samples 74 respondents have access to loan.

Table 3: Access to loan and women empowerment

\begin{tabular}{|c|c|c|c|c|}
\hline \multirow{2}{*}{$\begin{array}{c}\text { Borrowing } \\
\text { amount }\end{array}$} & \multicolumn{2}{|c|}{ Purpose of borrowing } & \multirow{2}{*}{ Total } & \multirow{5}{*}{$\begin{array}{l}\chi 2= \\
11.5416 \\
(0.000681) \\
*\end{array}$} \\
\hline & $\begin{array}{c}\text { Entrepreneurial } \\
\text { activities }\end{array}$ & $\begin{array}{c}\text { Non-Entrepreneurial } \\
\text { activities }\end{array}$ & & \\
\hline $\begin{array}{l}\text { Between 25,000- } \\
50,000\end{array}$ & 12 & 17 & 29 & \\
\hline Above 50,000 & 36 & 9 & 45 & \\
\hline Total & 48 & 26 & 74 & \\
\hline
\end{tabular}

Source: Sample Survey

(Figure in brackets is p-value, ${ }^{*}$ indicates significance at $5 \%$ level.)

As the table suggests there is association between access to loan and financial independence leading to economic empowerment of women $(\chi 2=11.5416, \mathrm{P}=0.000681)$. Taking up loans to start up business give women economic independence and thus makes them empowered.

To assess the association between access to insurance facilities and social security which leads to women empowerment, $\chi 2$ test of independence has been performed. Test results are given in Table 4. Out of 100 respondents, 96 of them have insurance coverage.

Table 4: Access to insurance and women empowerment

\begin{tabular}{|l|l|l|l|l|}
\hline Insurance amount & \multicolumn{2}{|c|}{ Source of insurance } & Total & \\
\cline { 2 - 4 } & Public sector & Private sector & & \multirow{2}{*}{$\boldsymbol{2}=13.2823$} \\
\hline 1-5 lakhs & 42 & 26 & 68 & \multirow{2}{*}{$(0.000268)^{*}$} \\
\hline Above 5 lakhs & 23 & 5 & 28 & \\
\hline Total & 65 & 31 & 96 & \\
\hline
\end{tabular}

Source: Sample Survey

(Figure in brackets is p-value, ${ }^{*}$ indicates significance at $5 \%$ level.)

As the table suggests there is association between access to insurance and social security because access to insurance means they are protected against any unforeseen risks and give women financial security in those circumstances, which in turn leads to women empowerment $(\chi 2=13.2823, \mathrm{P}=0.000268, \mathrm{P}<0.05)$.

It is noted that access to financial service through financial inclusion do have impact upon the social and financial empowerment of women leading to their overall empowerment.

\section{Conclusion}


This study mostly focuses on those women who are doing some entrepreneurial activities by taking up loans. We know financial inclusion is access to financial services like bank account, savings, credit, insurance etc. So, we can see that all the respondents have access to the financial services. When women have some saving they will be financially independent. They can take their own decisions. In the case of women who have taken up their own business are successful and are financially independent. These all leads to empowerment of women especially economic empowerment. Thus, proving the fact that financial inclusion leads to women empowerment.

\section{References}

[1] Chakraborty K. C. (2013), 'Financial Inclusion in India: Journey so far and way forward', RBI Bulletin.

[2] Mandira Sarma and JesimPaise(2008), 'Financial Inclusion and Development: A Cross Country Analysis',Indian Council for Research on International Economic Relations, pp 1-28.

[3] Michael Chibba (2009), 'Financial Inclusion, Poverty Reduction and the MDGs', European Journal of Development Research vol.21.

[4] Oya Pinar Ardic Maximilien Heimann Nataliya Mylenko (2011), 'Access to Financial Services and the Financial Inclusion Agenda around the World', The World Bank, pp 1-17.

[5] PratishaPadmasri Deka (2015) 'Financial Literacy and Financial Inclusion for Women Empowerment: A Study, International Journal of Applied Research.

[6] Singh Kuldeep and Singh Kondan (2012) 'Financial Inclusion, Development and Its Determinants: An Empirical Evidence of Indian states’ The Asian Economic Review Vol.53 (1).

\footnotetext{
*Corresponding author.

E-mail address: bincyg2@gmail.com/thomachandevagiri@ gmail.com
} 